\title{
Simulations of Flow Through the SSME LH2 Feed Line and LPFP Inducer
}

\author{
Daniel J. Dorney ${ }^{*}$ and Jeffry Rothermel ${ }^{\#}$ \\ NASA Marshall Space Flight Center \\ Applied Fluid Dynamics Analysis Group \\ MSFC, AL 35812
}

\begin{abstract}
During a post-flight inspection of the liquid hydrogen feed lines leading the Space Shuttle main engines cracks were discover in slots on a flow liner just upstream of the low pressure fuel pump inducer. Numerical simulations have been performed for the feed line, the flow liner (including the slots and backing cavity) and the inducer. The predicted results have been compared with experimental data taken during hot-fire tests at NASA Stennis Space Center.
\end{abstract}

\section{NOMENCLATURE}

$\begin{array}{ll}\mathrm{m} & \text { - mass flow }(\mathrm{lbm} / \mathrm{sec}) \\ \mathrm{P} & \text { - static pressure }(\mathrm{psia}) \\ \mathrm{Pt}(\mathrm{abs}) & \text { - absolute total pressure (psia) } \\ \mathrm{Pt}(\mathrm{rel}) & \text { - relative total pressure (psia) } \\ \mathrm{Tt}(\mathrm{abs}) & \text { - absolute total temperature (R) } \\ \mathrm{Tt}(\mathrm{rel}) & \text { - relative total temperature (R) } \\ \mathrm{W} & \text { - work based on mass-avg (BTU/lbm) } \\ \alpha & \text { - absolute circumferential flow angle, (deg) } \\ \beta & \text { - relative circumferential flow angle, (deg) } \\ \omega & \text { - RPM }\end{array}$

\section{INTRODUCTION}

During a routine post-flight inspection of the liquid hydrogen (LH2) feed lines leading to the Space Shuttle Main Engines (SSME) cracks were discovered between the slots of a flow liner just upstream of the low pressure fuel pump (LPFP) inducer. The flow liner is located at a gimbal joint and has two rows of 38 slots. The slots are used to clean bellows located in the cavity behind the liner. It was decided that simulations and experiments were necessary to determine the cause of the cracks, as well as to determine the risks posed by the cracks.

This paper presents the results of several numerical simulations for the LH2 feed line, the flow liner (including the slots and backing cavity) and the LPFP inducer. Prior to presenting the SSME simulations, results are presented for a benchmark simulation (water flow through a 90 degree elbow) to demonstrate the applicability of a compressible flow code to an incompressible flow. Results are then presented for the SSME and compared with experimental data obtained at NASA Stennis Space Center.

\section{NUMERICAL PROCEDURE}

The governing equations in the CFD analysis are the time-dependent, three-dimensional Reynoldsaveraged Navier-Stokes equations. The algorithm consists of a time marching, implicit, finite-difference scheme. The procedure is third-order spatially accurate and second-order temporally accurate. The inviscid fluxes are discretized according to the scheme developed by Roe [1]. The viscous fluxes are calculated using standard central differences. An approximate-factorization technique is used to compute the time rate changes in the primary variables. Newton sub-iterations are used at each global time step to increase stability and reduce linearization errors. For all cases investigated in this study, one Newton sub-iteration was performed at each time step. To extend the equations of motion to turbulent flows, an eddy viscosity formulation is used. The turbulent viscosity is calculated using the twolayer Baldwin-Lomax algebraic turbulence model [2]. The code has been parallelized using Message Passing Interface (MPI) and OpenMP application program interfaces (API's) to reduce the computation time for large-scale three-dimensional simulations.

The Navier-Stokes analysis uses O- and H-type zonal grids to discretize the flow field and facilitate relative motion of the rotating components. The O-grids are body-fitted to the surfaces of the airfoils and generated using an elliptic equation solution procedure. They are used to properly resolve the

* Aerospace Engineer, Associate Fellow AIAA.

\# Aerospace Engineer, Member AIAA. 
viscous flow in the blade passages and to easily apply the algebraic turbulence model. The algebraically generated $\mathrm{H}$-grids are used to discretize the remainder of the flow field.

\section{BOUNDARY CONDITIONS}

For incompressible inlet flow the mass flow, total temperature, and the circumferential and radial flow angles are specified as a function of the radius. The static pressure is extrapolated from the interior of the computational domain.

For incompressible outflow the circumferential and radial flow angles, total pressure, and the total temperature are extrapolated from the interior of the computational domain. The static pressure is specified at mid-span of the computational exit and the pressure at all other radial locations at the exit is obtained by integrating the equation for radial equilibrium. Periodicity is enforced along the outer boundaries of the $\mathrm{H}$-grids in the circumferential direction.

At solid surfaces the relative velocity is set to zero, the normal derivative of the pressure is set to zero, and the surfaces are assumed to be adiabatic.

Further details of the numerical procedure can found in Refs. [3] and [4].

\section{BENCHMARK TEST CASE}

The benchmark test case considers the flow of water through a 90-degree elbow [5]. Laser Doppler Velocimetry (LDV) and static pressure data were obtained as part of the experiments. The experiment was performed for a Reynolds number of 43,000 and a mass flow $3.5 \mathrm{lbm} / \mathrm{sec}$.

Two views of the computational grid are shown in Fig. 1. The computational grid contains 385 points in the streamwise direction, 93 points in the circumferential direction and 41 points in the radial direction.

Figure 2 shows a comparison of the predicted and experimental velocity contours 1.0 duct diameter downstream of the elbow. The predicted and experimental results exhibit good agreement.

Figure 3 shows a comparison of the predicted and experimental static pressure distributions in the region of the elbow. Good agreement exists between the predicted and experimental results, suggesting that the compressible flow code is suitable for certain incompressible flow simulations.

\section{SSME TEST CASE}

The numerical experiments with the SSME geometry are broken down into three categories:

1. simulations of the feed line up to the inducer

2. simulations of the feed line and inducer without the flow liner, slots or backing cavity; this is the configuration used in the initial hot-fire tests

3. simulations of the feed line, flow liner, slots, backing cavity and inducer

Figure 4 shows a schematic of the LH2 feed lines and the flow liner near the LPFP interface. The operating fluid in the feed lines is liquid hydrogen. The LH2 flows at approximately $158 \mathrm{lbm} / \mathrm{sec}$ in the line to each engine and has a pressure of 35 psig. The feed lines are approximately 12 inches in diameter, giving a mean velocity of approximately $48 \mathrm{ft} / \mathrm{sec}$. The LPFP inducer operates at 16,400 RPM for the $104 \%$ Rated Power Level (RPL).

The numerical simulations were performed on between 48 and 96 processors of an Origin3000 computer located at NASA Ames Research Center.

\section{Duct/BSTRA Simulations}

Simulations were performed for the curved portion of the feed line, along with the Ball Joint Structure Tripod Assembly (BSTRA). The BSTRA is used to allow flexure of the duct. Two views of the BSTRA in the straight portion of the feed line are shown in Fig. 5 .

Instantaneous velocity ( $\mathrm{ft} / \mathrm{sec}$ ) contours in the feed line are shown in Fig 6., while a close-up of the contours in the region of the BSTRA is shown in Fig. 7. Although vortices are shed from the tripod legs, the velocity fluctuations are damped out long before they reach the downstream flow liner. In addition, the pressure variations induced by the curved duct are small (see Fig. 8) and do not affect the flow liner.

Thus, the conclusion is drawn that the upstream influences (e.g., curvature of the duct and the BSTRA) did not induce the unsteadiness which causes the cracks at the flow liner slots.

\section{Duct/Inducer Simulations}

A series of duct/inducer simulations (without the flow liner, slots or backing cavity) was performed using a 
configuration similar to that used in experiments at Stennis Space Flight Center. The results of the simulations were supplied to stress engineers as pretest predictions.

The SSME LPFP inducer has four main blades and four splitter blades. It was decided that only the main blades would be used in the simulations because the splitter blades are located towards the downstream end of the inducer passage, and would have little effect on the unsteadiness at the flow liner. Note the splitter blades will, however, have an impact on the performance of the inducer. Figure 9 illustrates the computational grids for the duct and inducer, along with axial location where the downstream row of slots (which contained the majority of the cracks) would be located.

Figure 10 contains instantaneous static pressure contours and an axial velocity iso-surface highlighting $10 \mathrm{ft} / \mathrm{sec}$ back flow. The upstream propagating pressure waves and back flow are common to inducers and impellers. Figure 11 shows the results from a simulation with an extended feed line duct, highlighting the extent of the pressure wave propagation and backflow.

Figure 12 shows a comparison of the unsteadiness predicted in the current study with data recently obtained at NASA Stennis Space Center. The amplitude of the predicted complete unsteady pressure at the downstream slot location matches well with the experimental data. It should be noted, however, that the predicted unsteady pressure spectrum is different from the experimental spectrum because the current simulations assume single-phase flow. The flow in the experimental apparatus contains significant amount of cavitation bubbles in the back flow, which will modify the frequency spectrum. Thus, the predicted results indicate much stronger unsteadiness at the inducer blade passing frequency, while the experimental data shows a wide array of frequencies.

\section{Duct/Flow Liner/Cavity/Inducer Simulations}

Figure 13 shows the instantaneous static pressure along the wall of the duct, mid-height of the cavity behind the slots and on the suction side of the inducer blades.

Figure 14 shows the pressure difference across the flow liner, along with frequency spectrum at a downstream slot. The slots experience a pressure difference of up to 15 psi across the liner (duct side to cavity side).

\section{CONCLUSIONS}

A series of unsteady three-dimensional Navier-Stokes simulations has been performed to support the investigation of cracks in the SSME LH2 feed line flow liner.

The final paper will include more detailed discussion of the results, as well as comparisons with additional computational and experimental data.

\section{ACKNOWLEDGEMENTS}

The authors would like to acknowledge the use of the supercomputer facilities at NASA Ames Research Center, and especially thank Mr. Chuck Niggley for his assistance.

\section{REFERENCES}

1. Roe, P. L., "Approximate Riemann Solvers, Parameter Vectors, and Difference Schemes," Journal of Computational Physics, Vol. 43, 1981, pp. 357-372.

2. Baldwin, B. S., and Lomax, H., "Thin Layer Approximation and Algebraic Model for Separated Turbulent Flow," AIAA Paper 78-257, Huntsville, AL, January, 1978.

3. Griffin, L. W. and Dorney, D. J., "Simulations of the Unsteady Flow Through the Fastrac Supersonic Turbine," ASME Journal of Turbomachinery, Vol. 122, No. 2, April, 2000, pp. 225-233.

4. Dorney, D. J., Griffin, L. W., and Huber, F., "'A Study of the Effects of Tip Clearance in a Supersonic Turbine," ASME Journal of Turbomachinery, Vol. 122, No. 4, October, 2000, pp. 674-673.

5. Enayet, M. M., Gibson, M. M., Taylor, A. M. K. $P$. and Yianneskis, M. "Laser-Doppler Measurements of Laminar and Turbulent Flow in a Pipe Bend," Int. J. Heat \& Fluid Flow, 1982, Vol. 3, pp. 213-219. 

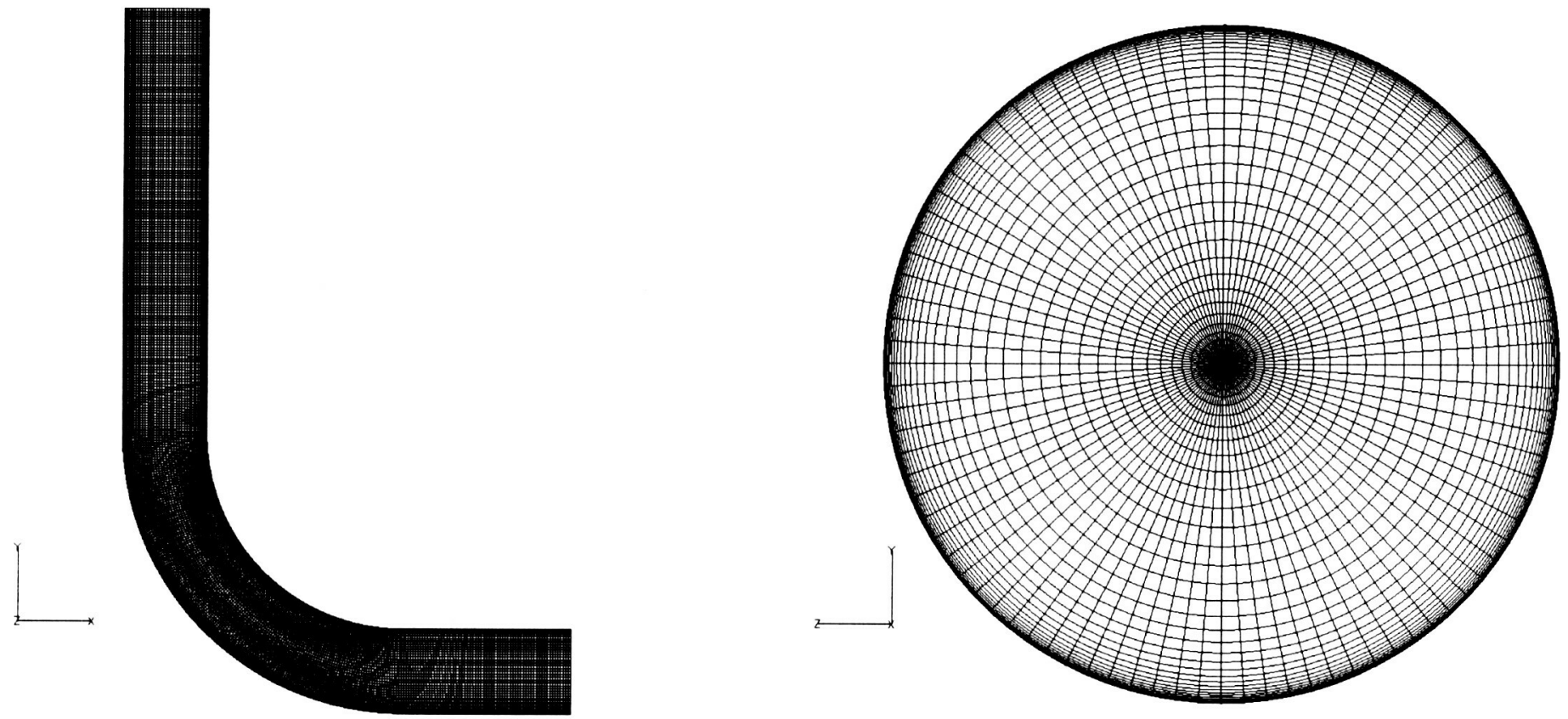

Figure 1. Two views of the computational grid for the elbow. 


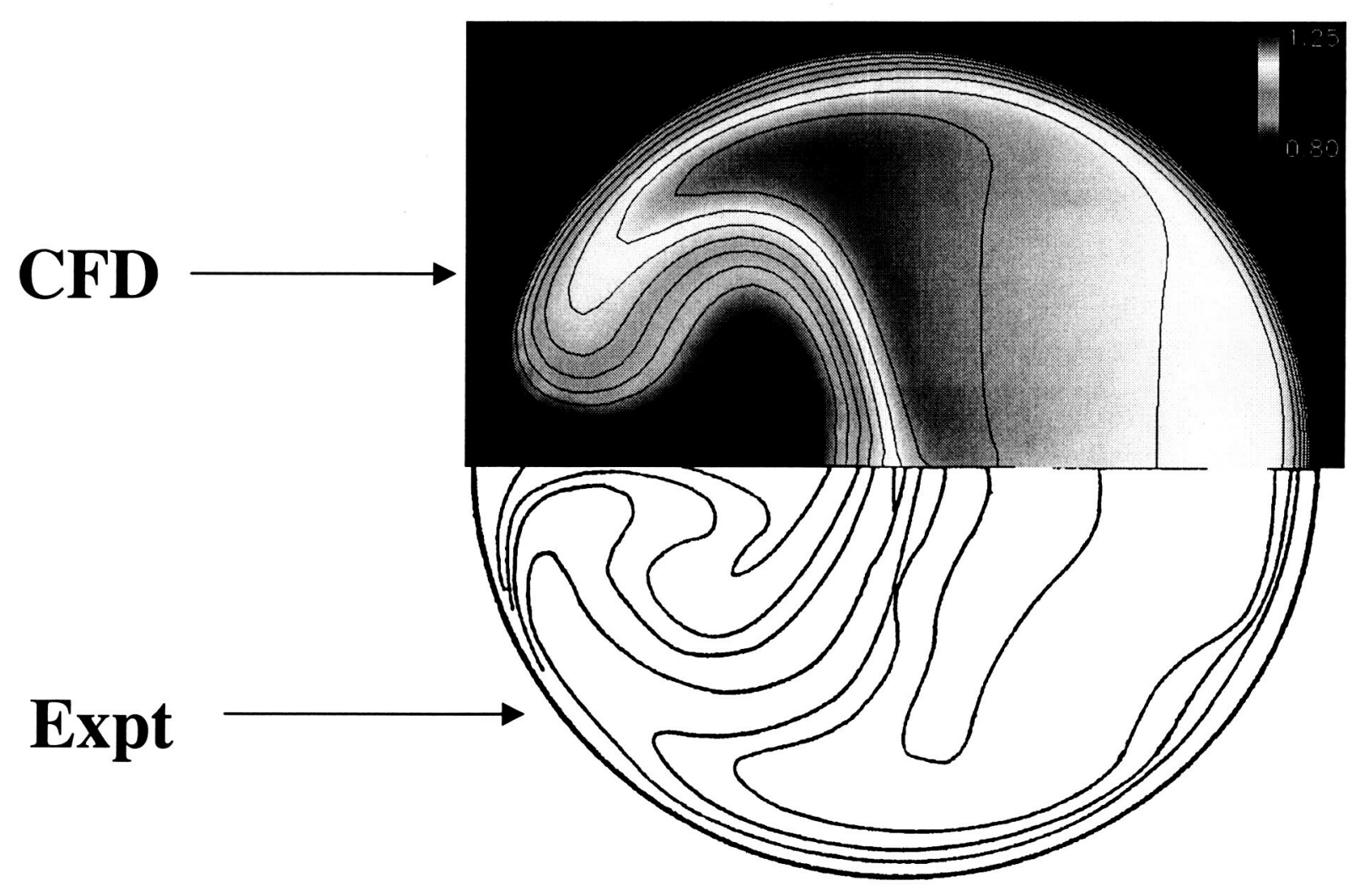

Figure 2. Comparison of predicted and experimental non-dimensional velocity contours 1.0 duct diameters downstream of the elbow. 

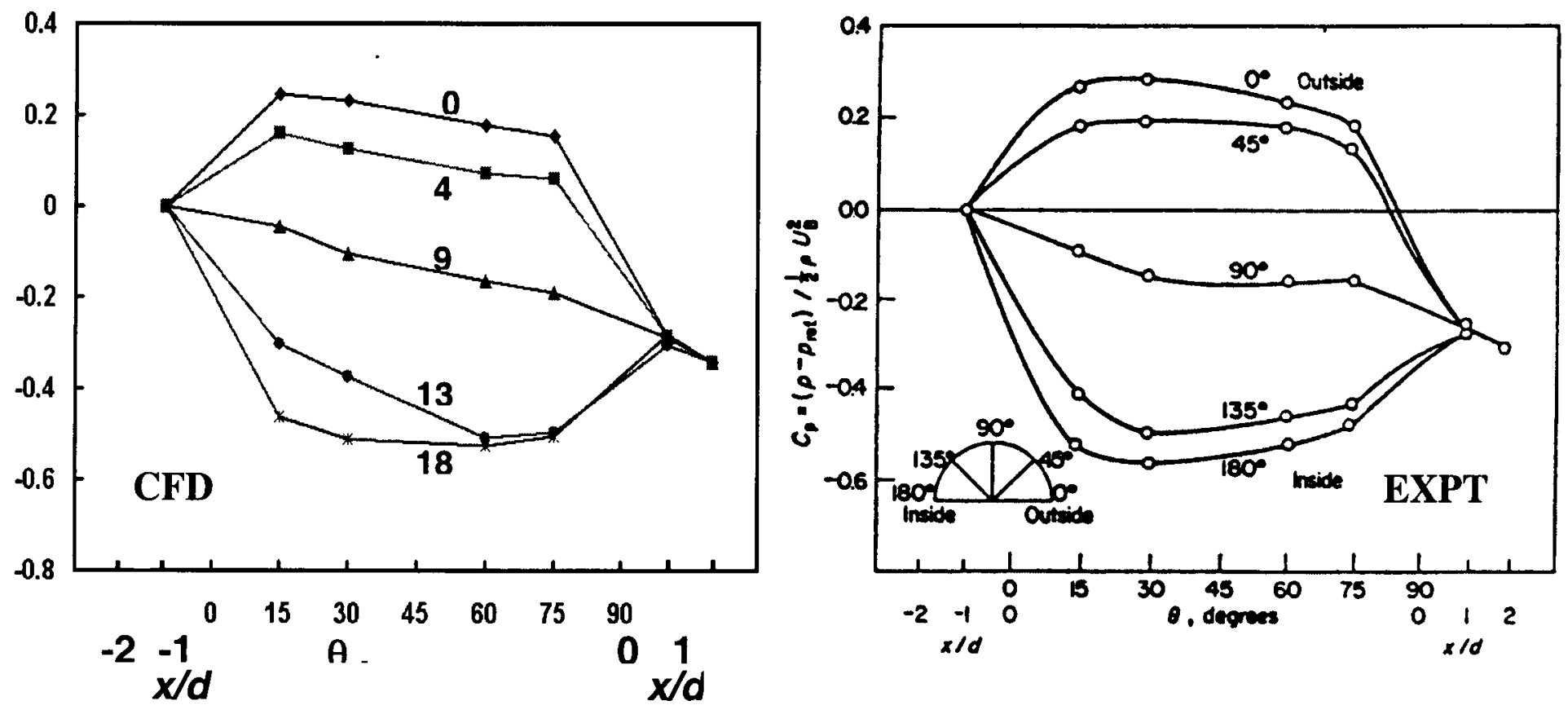

Figure 3. Predicted and experimental static pressure distributions in the region of the elbow. 


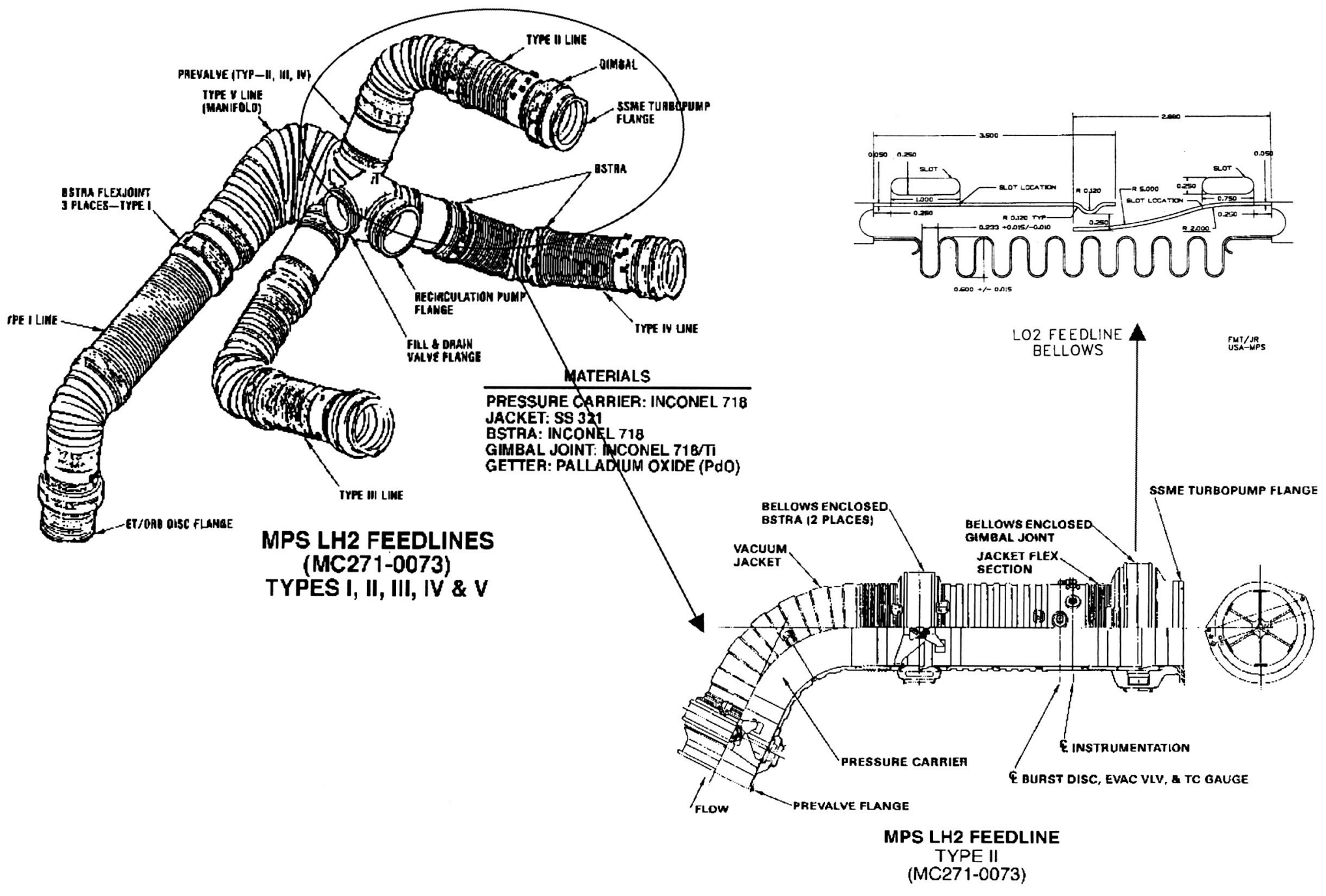

Figure 4. LH2 feed lines and flow liner. 


\section{Liner Details}
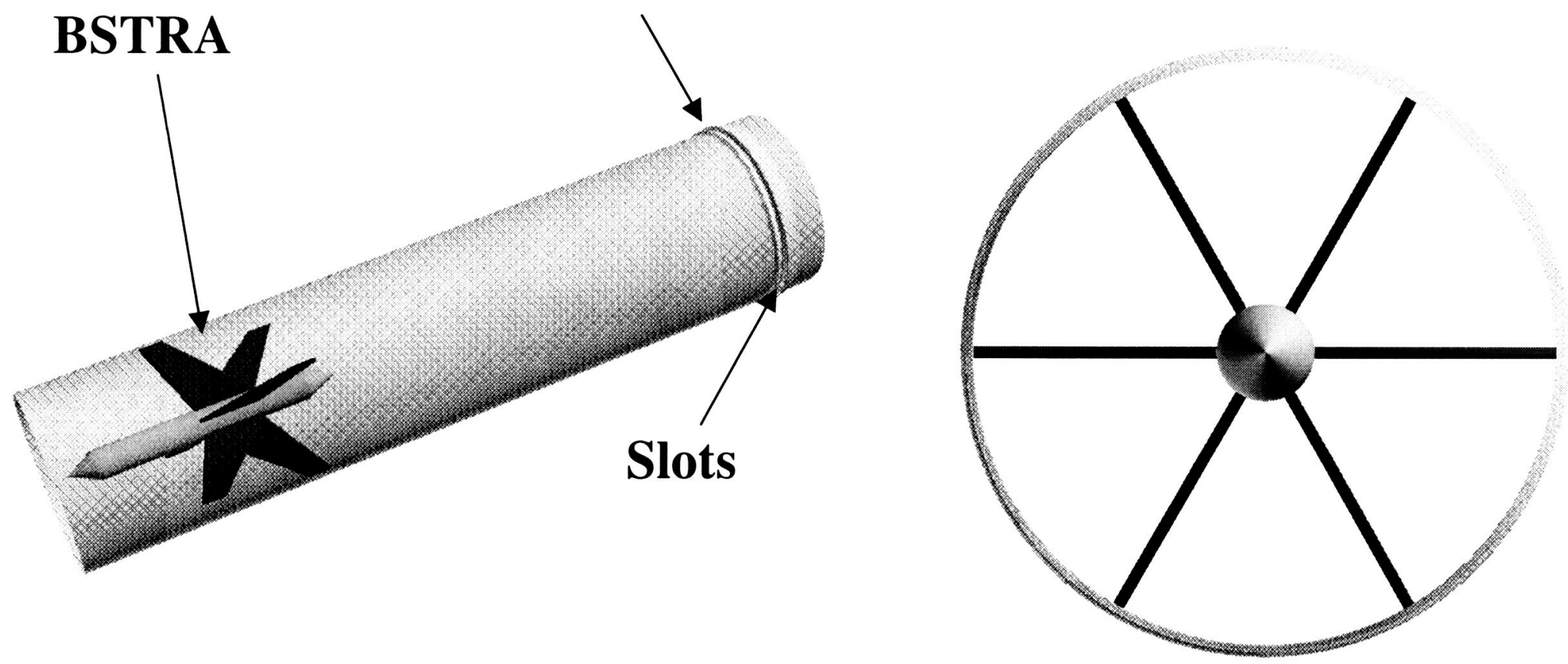

View from Upstream

Figure 5. Two views of the BSTRA in the straight portion of the feed line. 


\section{Circumferential velocity distortion due to bend

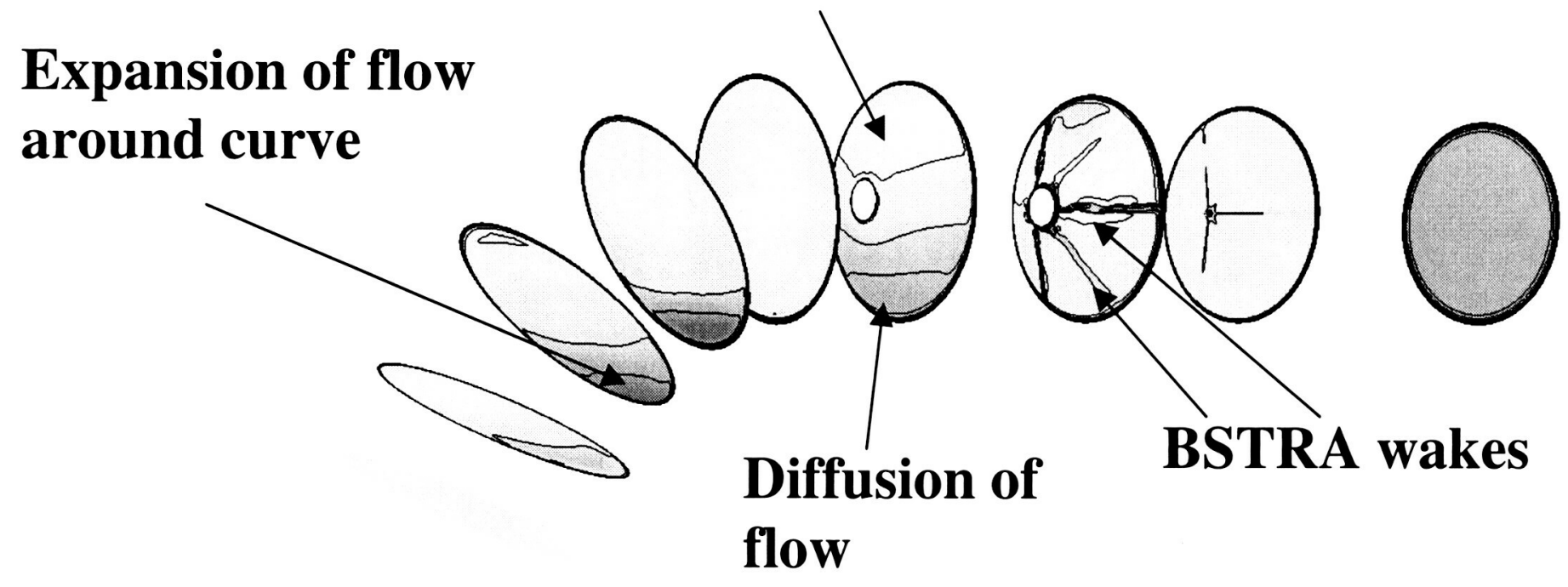

Figure 6. Instantaneous velocity in the LH2 feed line. 


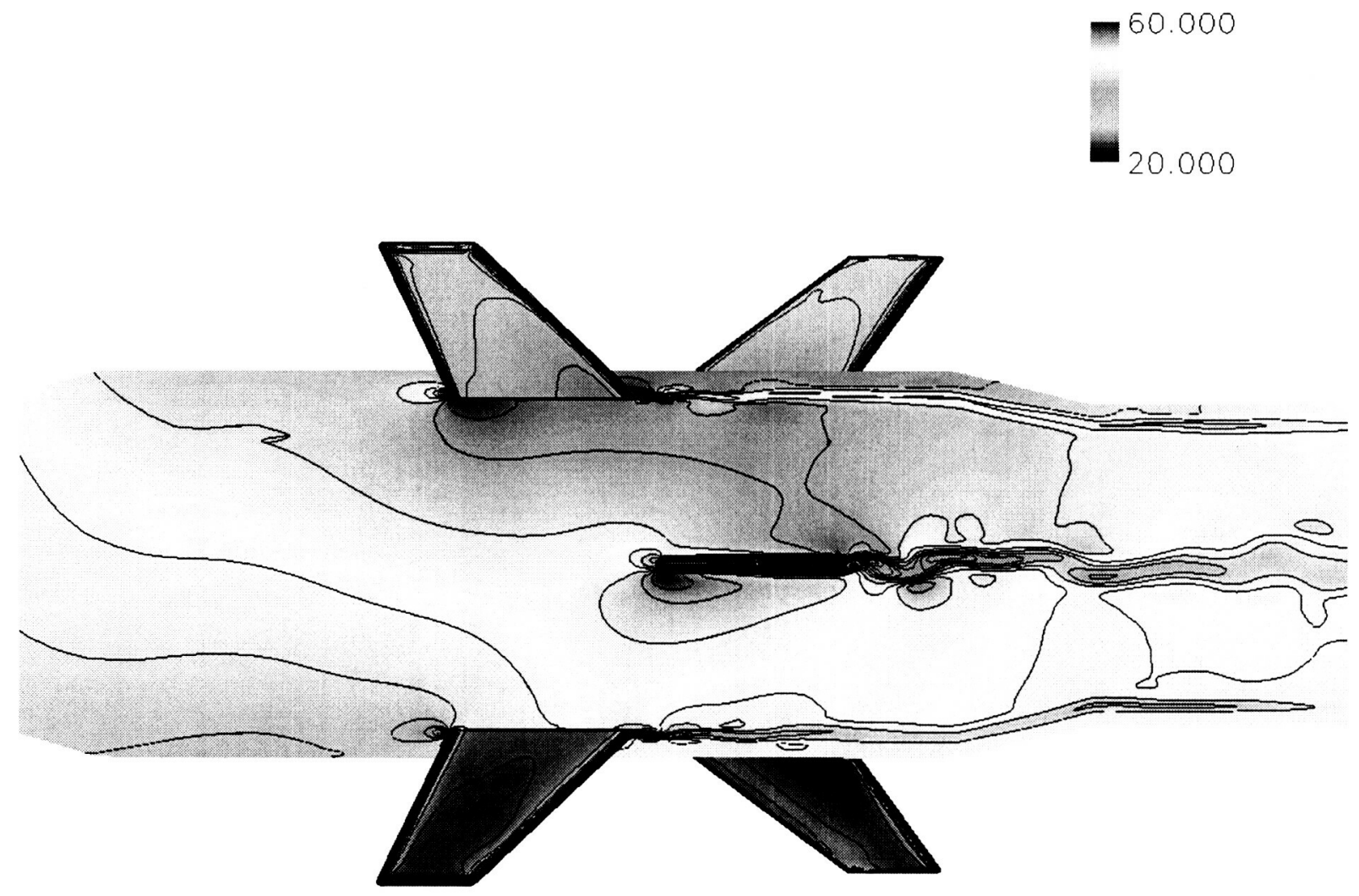

Figure 7. Instantaneous velocity ( $\mathrm{ft} / \mathrm{sec}$ ) contours in the region of the BSTRA. 


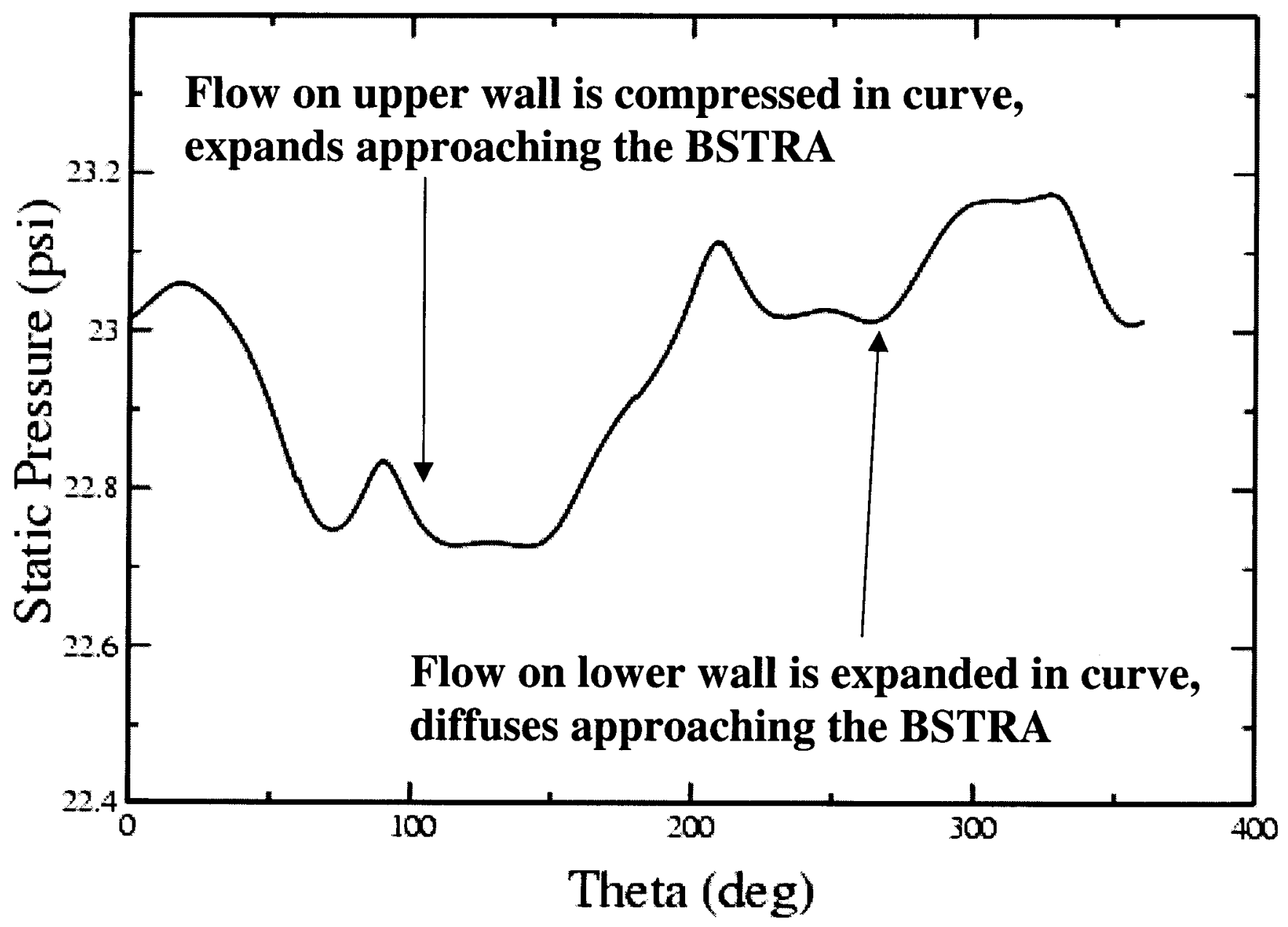

Figure 8. Circumferential variation of the static pressure downstream of the curve in LH2 feed line. 


\section{Axial location corresponding to slots}

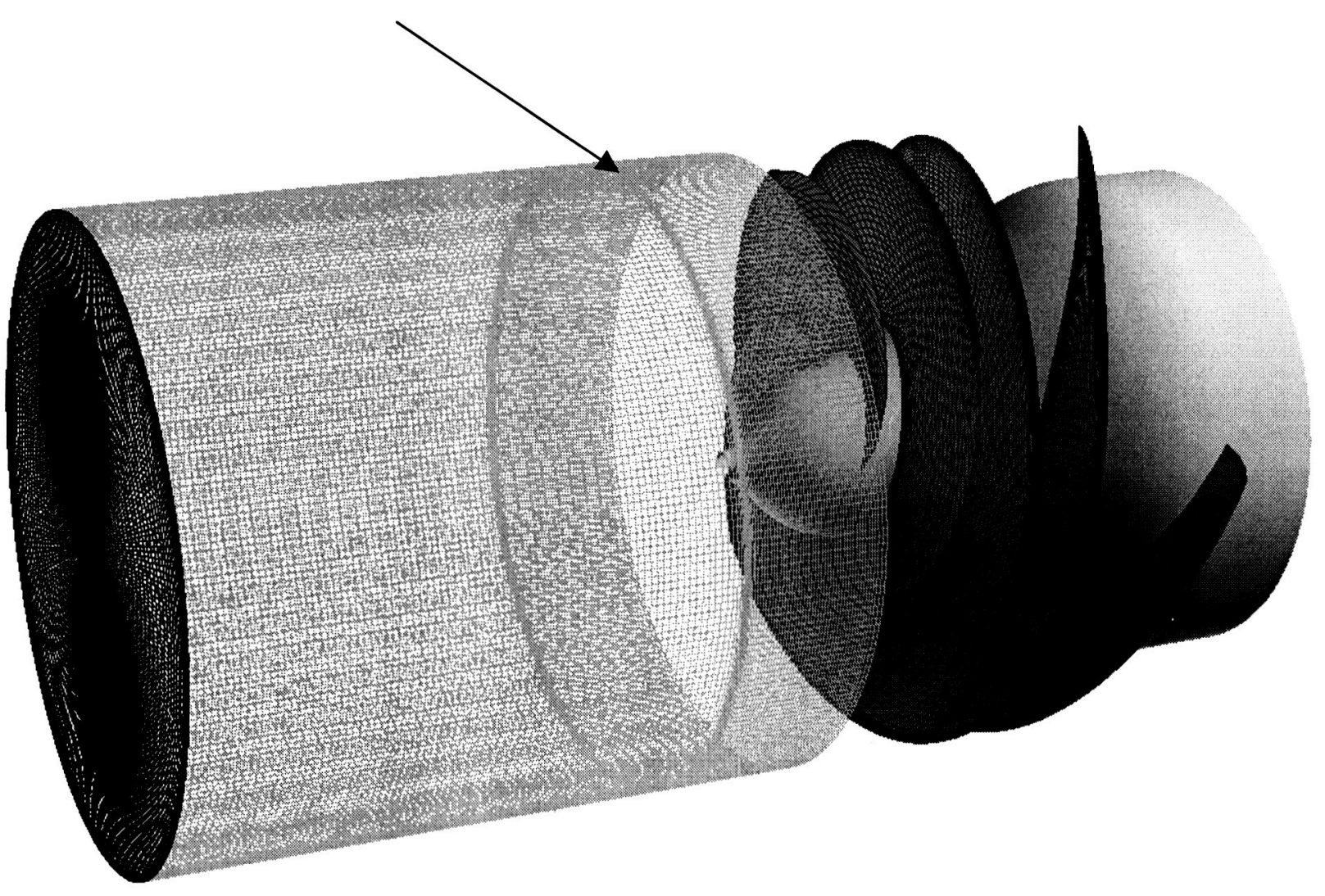

Figure 9. Computational grids for the duct/inducer simulation. 


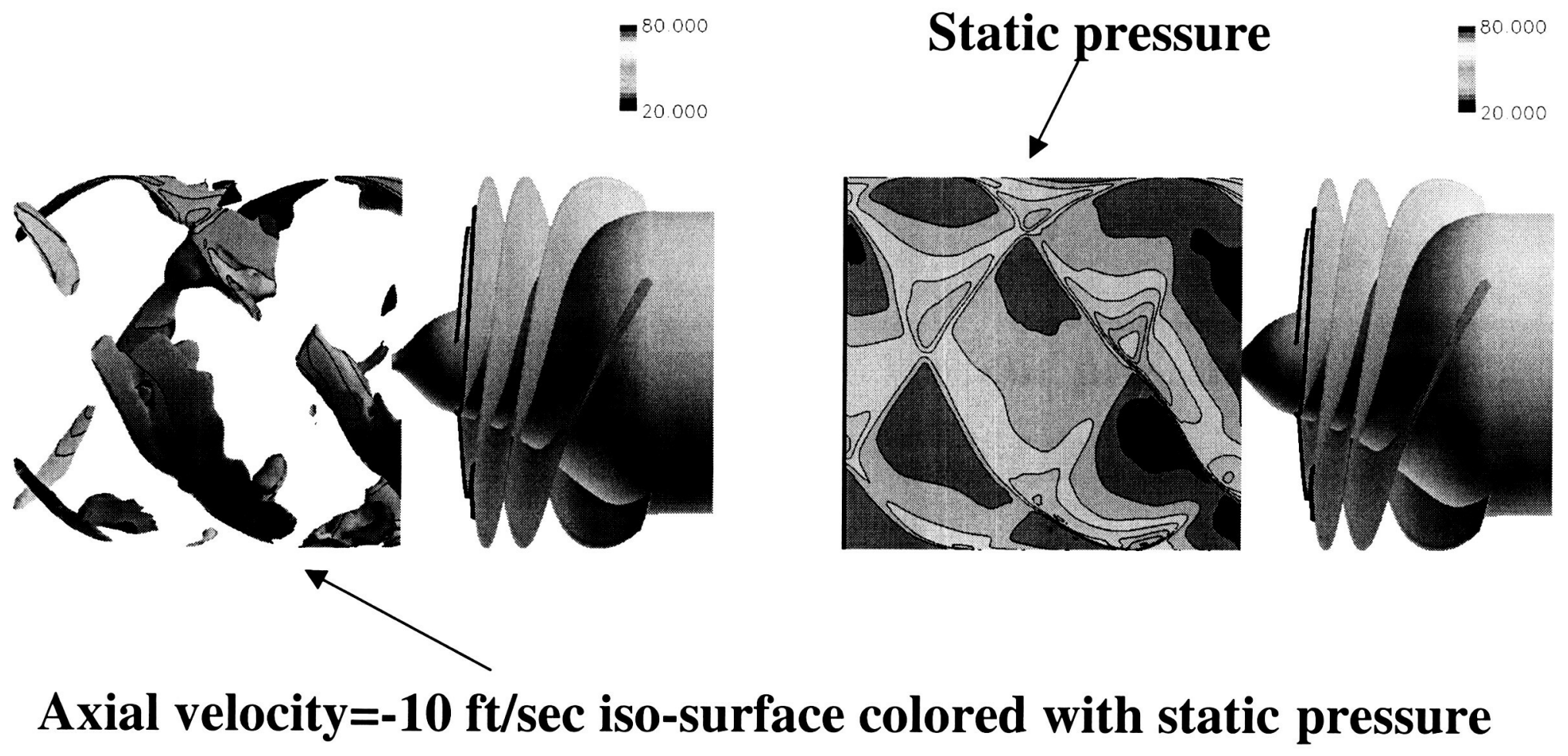

Figure. 10. Instantaneous static pressure and iso-surface of axial velocity. 


\section{5 psig pressure iso-surface colored bv axial velocitv}

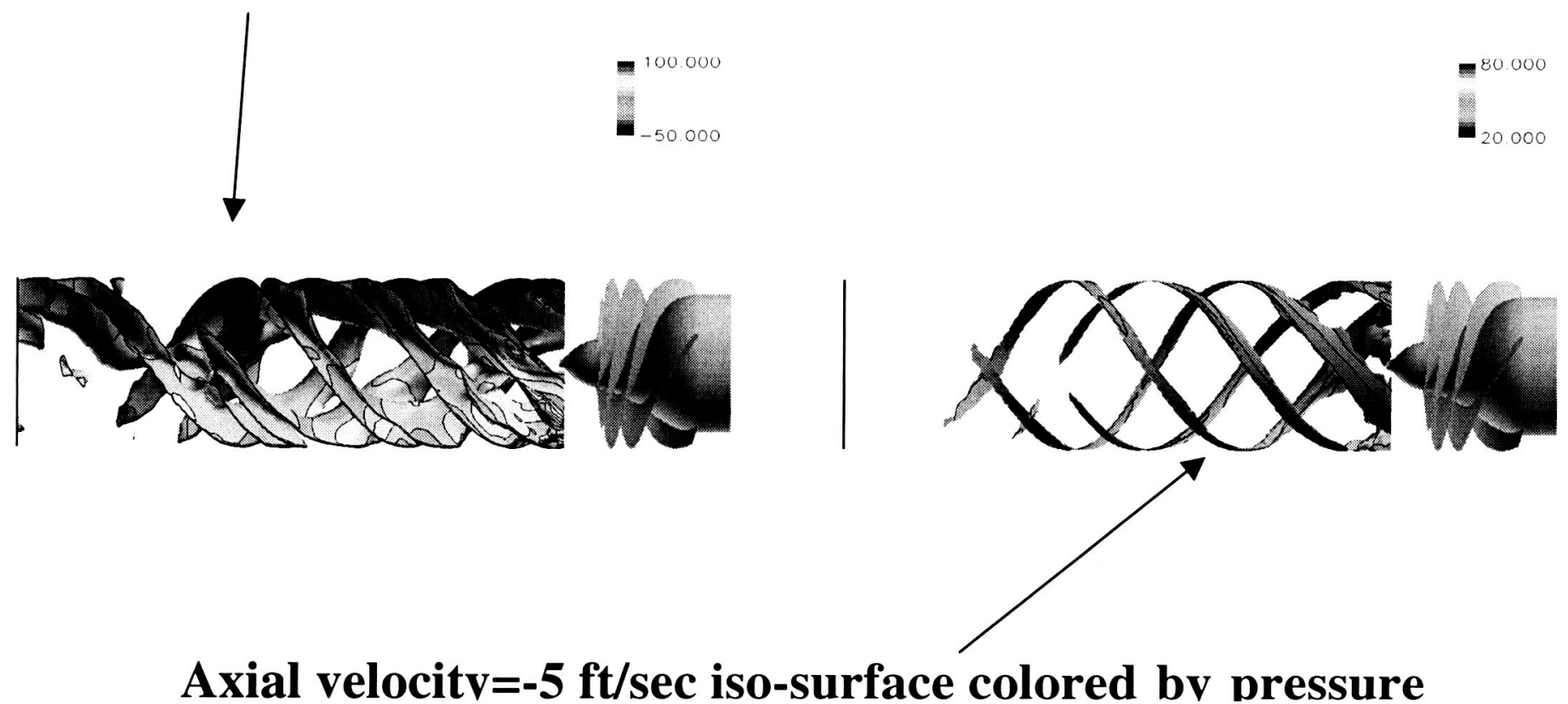

Figure 11. Extent of pressure wave propagation and back flow on an extended duct grid. 


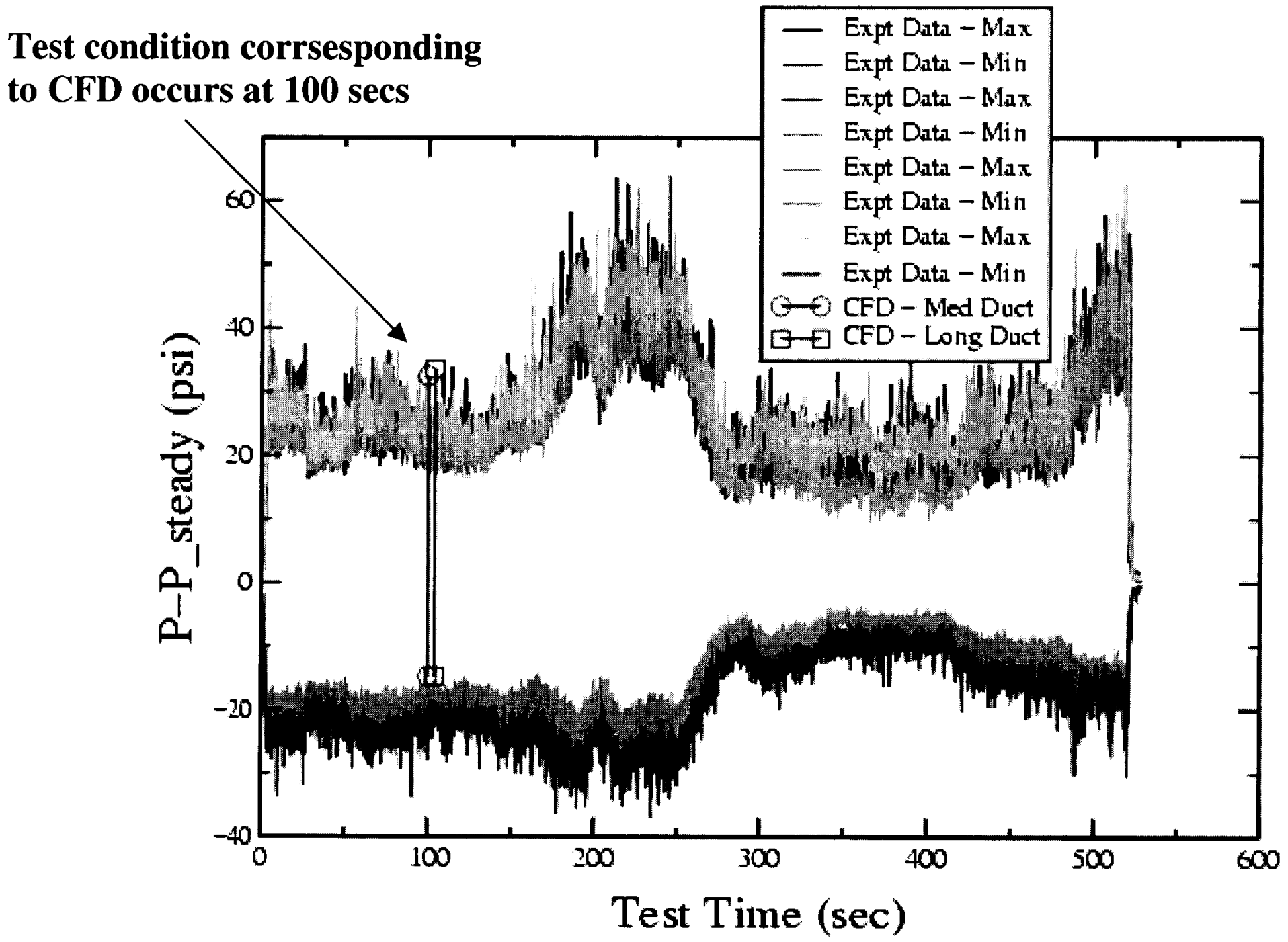

Figure 12. Comparison of predicted and experimental unsteadiness at 104\% RPL. 


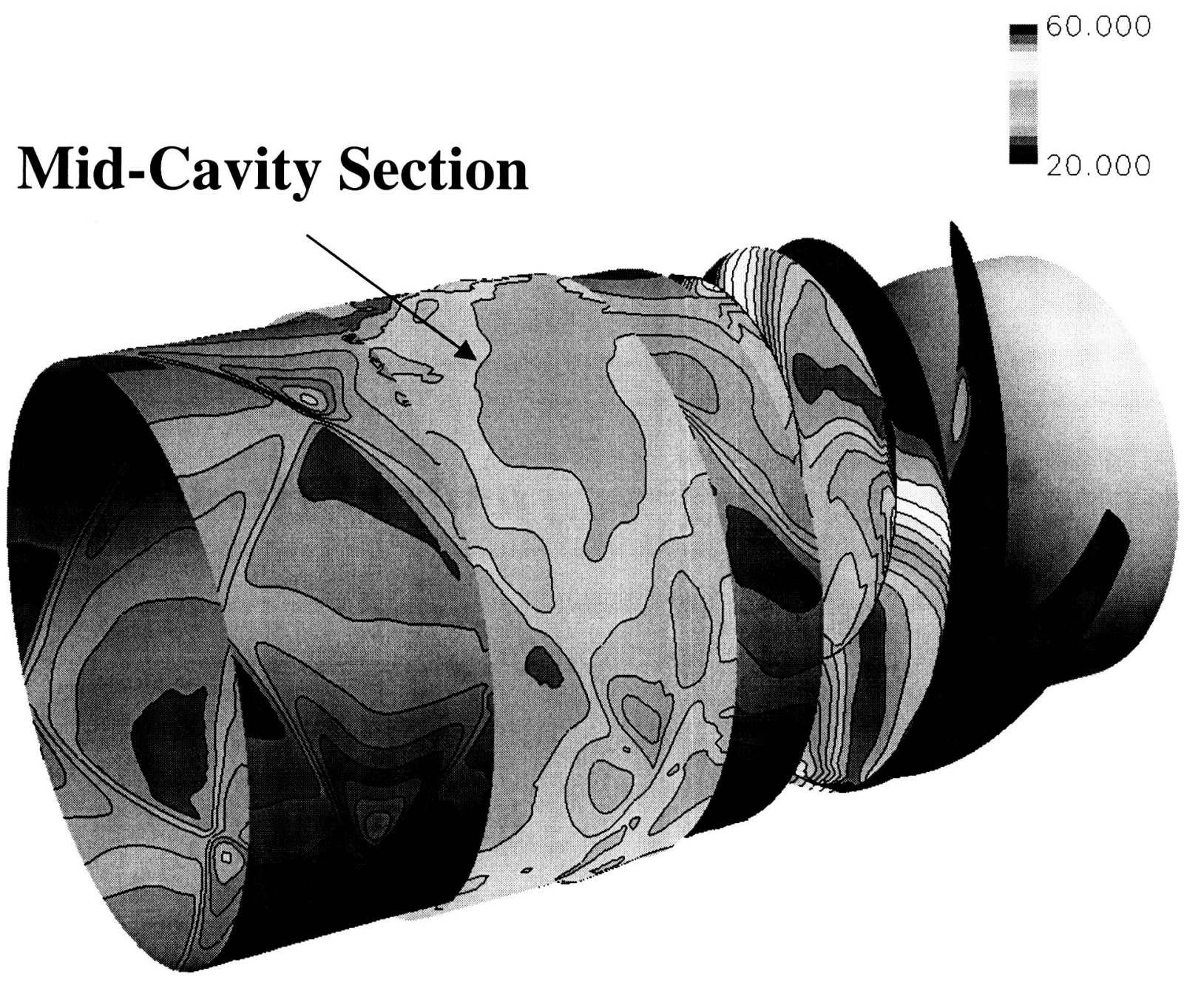

Figure 13. Instantaneous static pressure on the duct wall, mid-cavity and on the inducer blades. 


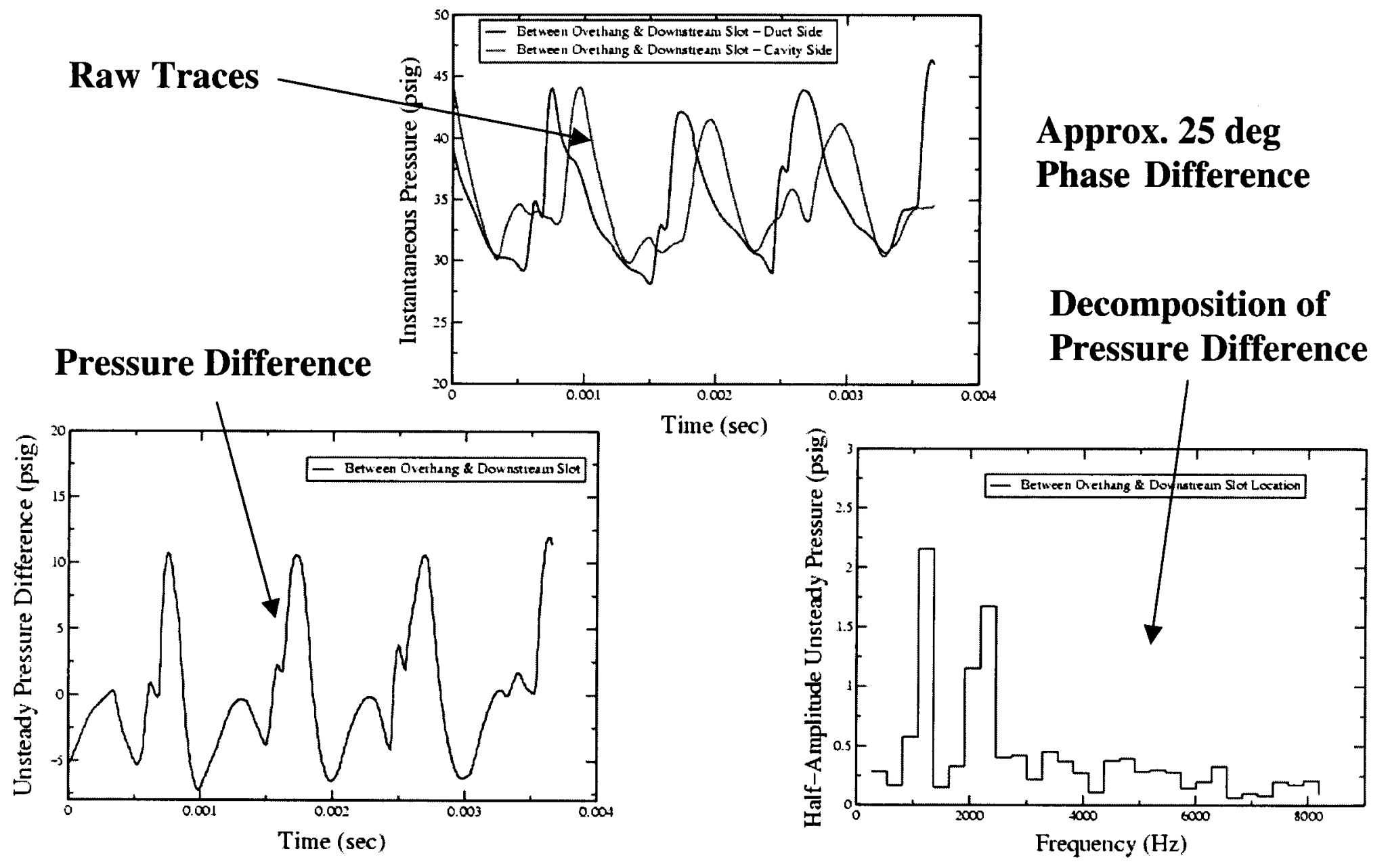

Figure 14. Unsteady pressure at the downstream slot location. 